\title{
Global Burden of Influenza as a Cause of Cardiopulmonary Morbidity and Mortality
}

\author{
William A. Fischer $\mathrm{II}^{* \dagger}$, Michelle Gong ${ }^{\ddagger}$, Satish Bhagwanjee ${ }^{\S}$, Jonathan Sevransky ${ }^{\prime}$ \\ Chapel Hill, NC, USA; Bronx, NY, USA; Seattle, WA, USA; and Atlanta, GA, USA
}

\begin{abstract}
Severe acute respiratory infections, including influenza, are a leading cause of cardiopulmonary morbidity and mortality worldwide. Until recently, the epidemiology of influenza was limited to resource-rich countries. Emerging epidemiological reports characterizing the $2009 \mathrm{H} 1 \mathrm{Nl}$ pandemic, however, suggest that influenza exerts an even greater toll in low-income, resource-constrained environments where it is the cause of $5 \%$ to $27 \%$ of all severe acute respiratory infections. The increased burden of disease in this setting is multifactorial and likely is the result of higher rates of comorbidities such as human immunodeficiency virus, decreased access to health care, including vaccinations and antiviral medications, and limited healthcare infrastructure, including oxygen therapy or critical care support. Improved global epidemiology of influenza is desperately needed to guide allocation of life-saving resources, including vaccines, antiviral medications, and direct the improvement of basic health care to mitigate the impact of influenza infection on the most vulnerable populations.
\end{abstract}

Severe acute respiratory infections (SARI) including influenza represent a leading cause of global morbidity and mortality. Each year, an estimated 5\% to 10\% of adults and $20 \%$ to $30 \%$ of children are infected with influenza, resulting in 3 to 5 million cases of severe disease and approximately 1 million deaths worldwide [1]. Until recently, the epidemiology of influenza has been primarily derived from resourcerich settings. Emerging data from the $2009 \mathrm{H} 1 \mathrm{Nl}$ pandemic, however, suggests that influenza exerts an even greater toll on patients in resource-limited environments due to decreased access to health care, limited healthcare infrastructure, and shortages of healthcare personnel. This includes poor availability of vaccinations and critical care support, and the high prevalence of comorbidities such as human immunodeficiency virus (HIV) infection and malnutrition.

Influenza is a respiratory virus that, despite the availability of vaccines and effective antiviral medications, exerts a substantial toll on global morbidity and mortality every year. Seasonal influenza is often clinically mild, recognized by a constellation of symptoms including fever and cough or sore throat, which is classified as "influenza-like illness" (ILI) in the absence of a known cause other than influenza [2]. More severe influenza infections can occur and are further classified as SARI if the patient with ILI has shortness of breath [3]. Pandemics occur when a novel influenza virus enters into the human population and is capable of spreading rapidly. The most severe pandemic occurred in 1918 when an influenza virus crossed over from birds to humans and killed an estimated 50 to 100 million people with a mortality rate of approximately $2 \%$ to $2.5 \%$ [4]. Recently, a number of influenza viruses (H5N1 and H7N9) have emerged with pandemic potential and even greater mortality rates of up to $60 \%$, but they have not yet reached sustained transmission in humans $[5,6]$. In April
2009, a novel strain of H1Nl influenza jumped from swine into humans and infected over 200 million people globally, resulting in the first influenza pandemic of the 21 st century. Despite a wealth of information about influenza from resource-rich countries, very little is known about influenza's epidemiology and sequelae in resource-limited countries.

Given the global impact of influenza and the paucity of data for many countries, this review represents an initial step to better characterize the burden of influenza including epidemiology, sequelae of severe influenza infection, and strategies to improve supportive care and virus-specific therapy in resource-limited, low-income settings. The review will examine the available epidemiology in resourcelimited countries with a specific focus on the first year of the $2009 \mathrm{HlNl}$ pandemic as well the known risk factors for influenza in these settings. The most prominent sequelae of infection including cardiopulmonary complications will then be reviewed. Finally, it will consider treatment and remaining barriers to improving influenza care globally.

\section{SENTINEL SURVEILLANCE OF 2009 PANDEMIC H1N1 INFLUENZA IN LOW- AND LOW-MIDDLE- INCOME COUNTRIES}

Since the outbreak of avian H5N1 influenza in 1997, there has been growing recognition of the need for improved global surveillance of influenza. In response, the World Health Organization (WHO) launched the Global Agenda for Influenza Surveillance and Control in 2001, which prioritized influenza surveillance as part of a comprehensive strategy to reduce morbidity and mortality from annual influenza epidemics [7]. Despite the implementation of basic influenza surveillance systems across the globe, very little was reported about seasonal influenza in resource-limited areas.
This work was supported by grants from the National Institutes of Health (\#AG045088 [W.F.] and KL2TR001109), the Infectious Disease Society of America Young Investigator Award in Geriatrics (W.F.), the Association of Specialty Providers T. Franklin Williams Award (W.F.), and a Center for AIDS Research Award (W.F.). Dr. Gong has received research funding from the National Heart, Lung, and Blood Institute (HL10871203, HL12299801, HL12511901) and the Centers from Medicaid and Medical Services. The other authors report no relationships that could be construed as a conflict of interest.

From the * Division of Pulmonary and Critical Care Medicine, Department of Medicine, The University of North Carolina at Chapel Hill School of Medicine, Chapel Hill, NC, USA; †The Center for Environmental Medicine, Asthma and Lung Biology, The University of North Carolina at Chapel Hill School of Medicine, Chapel Hill, NC, USA; $\ddagger$ Albert Einstein College of Medicine, Bronx, NY, USA; $\S$ Department of Anesthesiology and Pain Medicine, University of Washington, Seattle, WA, USA; and the ||Division of Pulmonary, Allergy and Critical Care Medicine, Emory University, Atlanta, GA, USA. Correspondence: W. A. Fischer II (William_Fischer@med. unc.edu).

GLOBAL HEART (C) 2014 World Heart Federation (Geneva). Published by Elsevier Ltd. All rights reserved. VOL. 9, NO. 3, 2014 ISSN 2211-8160/\$36.00. http://dx.doi.org/10.1016/ j.gheart.2014.08.004 
The global spread of pandemic H1N1 in 2009 represented the first influenza pandemic of the 21 st century. Within a year, cases were reported in more than 214 countries, overseas territories, and communities [8]. On June 11, 2009, WHO raised the pandemic alert to a level 6 , the highest level, indicating evidence of sustained human-tohuman transmission and global spread of this virus. In the United States alone, there were an estimated 59 million illnesses, 265,000 hospitalizations, and 12,000 deaths as of February 2010 [9]. The pandemic was declared over in August 2010 but not before an estimated 200 million people were infected [8]. Approximately 18,500 laboratoryconfirmed deaths due to $\mathrm{H} 1 \mathrm{Nl}$ were reported to $\mathrm{WHO}$. However, these numbers are likely a gross underrepresentation of the true burden of global influenza due to a lack of standardized case reporting or access to health care [10]. Early reports of high morbidity and mortality from Mexico, an upper-middle-income country according to the World Bank, suggested that an excess in mortality and life years lost occurs in more resource-limited settings [11]. Furthermore, of the 18,500 2009 pandemic H1N1 (pH1N1) influenza deaths reported to WHO, only 168 (0.9\%) were from Africa, despite its being home to $12 \%$ of the world's population [12]. The juxtaposition between the large numbers of people living in low-income countries and the small numbers of infections and deaths due to $2009 \mathrm{pH} 1 \mathrm{Nl}$ influenza in these settings highlighted the gap in the current understanding of the global burden of influenza.

To better characterize the effect of influenza infection in resource-limited or low-income areas, we performed a comprehensive search of articles related to the $2009 \mathrm{H} 1 \mathrm{~N} 1$ pandemic influenza in low-income and lower-middle-income countries using the following combined search terms: "(swine or H1N1) and (flu or influenza or virus or outbreak or pandemic) and (Africa or Southeast Asia or India or Eastern Europe or resource limited or low income)." A total of 1,941 articles were identified and evaluated for content, including primary data related to sentinel surveillance of patients with influenza between 2009 and 2010. Of those, 1,823 studies were excluded, as they did not contain primary data relevant to this study. The remaining 118 were reviewed and 97 were excluded as they did not report data from low-income countries or included only pediatric populations. We analyzed the subsequent 21 articles to characterize the sentinel surveillance of the $2009 \mathrm{H} 1 \mathrm{Nl}$ influenza pandemic in lowincome countries (Table 1) [13-23].

\section{North Africa}

Morocco. Morocco is a country of 33 million people located in Northwest Africa [24]. In line with the WHO Global Agenda for Influenza Surveillance and Control, Morocco strengthened influenza sentinel surveillance in 2007. As a result, 3,102 respiratory samples were collected between 2007 and 2009 with 98 (3\%) of these samples positive for influenza [20]. The emergence of the 2009 $\mathrm{H} 1 \mathrm{~N} 1$ pandemic led to increased surveillance resulting in the collection of 3,937 samples between June 2009 and February 2010 alone [15]. Of these, approximately 1,452 (37\%) tested positive for 2009 pandemic H1N1 influenza. Approximately $40 \%$ of patients who presented with ILI and 27\% with SARI were positive for 2009 pH1N1 [15]. The largest number of patients with ILI and SARI occurred in children under 15 (56\% and 51\%, respectively) [15,19]. Sixty-four patients (19\%) admitted with SARI died, which highlights the poor outcome of severe influenza in Morocco. Whereas severe disease was observed with similar frequency in all age groups ( $19 \%$ in children $<5$ years, $33 \%$ in children 5 to $14,27 \%$ in those 15 to $24 ; 33 \%$ in those 25 to 59 , and $25 \%$ in those $>60$ ), death occurred to a greater extent in adults between the ages of 25 and 59 years, which is similar to that found in the United States and Europe. Influenza in Morocco was seasonal with peak transmission between October and April [20]. Influenza vaccination was reported in only $2 \%$ to $4 \%$ of patients presenting with ILI or SARI [20]. The high proportion of patients presenting with ILI and SARI due to influenza suggests that influenza may be a leading cause of vaccine-preventable respiratory infection and mortality in North Africa.

\section{West Africa}

Guinea, Mali, and Niger. Despite the fact that by December 2009, approximately $92 \%$ of countries worldwide had reported $\geq 1$ case of $2009 \mathrm{HlNl}$ influenza, $75 \%$ of countries (12 of 16) in West Africa had yet to report a single case [18]. In an attempt to understand the transmission of 2009 pandemic H1N1 in Africa, surveillance data was obtained from 10 countries during the 2009 pandemic [18]. Between May 4, 2009, and April 3, 2010, a total of 10,203 respiratory samples were tested, of which $25 \%$ were positive for H1N1 pandemic influenza [18]. Between May 2009 and April 2010, 12 of 98 (12\%), 53 of 422 (13\%), and 90 of 388 (23\%) samples were positive for influenza in Guinea, Mali and Niger, respectively. The 2009 pandemic H1Nl virus was first detected in Cape Verde and Cote d'Ivoire in June 2009 followed by Ghana and Cameroon (August 2009); Mauritania, Guinea, and Senegal (December 2009); Mali (January 2010); and finally Niger in February 2010 [18]. Only 14\% of samples tested through the end of December 2009 were positive for the $2009 \mathrm{H} 1 \mathrm{Nl}$ pandemic strain, indicating that the belated detection of cases in Mauritania, Guinea, Senegal, Mali, and Niger truly represented a delayed spread of the 2009 H1N1 influenza virus in West Africa [18].

Nigeria. As the most populous country in Africa (173 million people), Nigeria only expanded influenza sentinel surveillance in 2008, building on a foundation established as part of WHO's African Region's Integrated Disease Surveillance and Response strategy [25]. Between 2009 and 2010, 2,803 samples were obtained from patients presenting with ILI or SARI (412 were unclassified as either ILI or SARI) from 4 sentinel sites [16]. Of these, 217 patients (8\%) tested 
TABLE 1. Influenza sentinel surveillance in low- and lower-middle-income countries during the first year of the 2009 H1N1 influenza pandemic

\begin{tabular}{|c|c|c|c|c|c|c|c|}
\hline Country (Region) & Income & $\begin{array}{l}\text { Population } \\
\text { (Millions)* }^{*}\end{array}$ & Date of Surveillance & $\begin{array}{c}\text { Total } \\
\text { Samples }\end{array}$ & $\begin{array}{l}\text { Influenza } \\
\text { Positive, } \\
\text { n (\%) }\end{array}$ & $\begin{array}{l}\text { ILI Positive for } \\
\text { Influenza, n (\%) }\end{array}$ & $\begin{array}{l}\text { SARI Positive } \\
\text { for Influenza, } \\
\text { n (\%) }\end{array}$ \\
\hline \multicolumn{8}{|l|}{ North Africa } \\
\hline Morocco & Lower middle & 33 & $\begin{array}{l}\text { June 2009-February } \\
2010\end{array}$ & 3,937 & $1,452(37)^{\dagger}$ & $1,056(40)^{\dagger}$ & $342(27)^{\dagger}$ \\
\hline \multicolumn{8}{|l|}{ West Africa } \\
\hline Guinea & Low & 12 & May 2009-April 2010 & 98 & $12(12)$ & NR & NR \\
\hline Mali & Low & 15 & May 2009-April 2010 & 422 & $53(13)$ & NR & NR \\
\hline Niger & Low & 18 & May 2009-April 2010 & 388 & $90(23)$ & NR & NR \\
\hline Nigeria & Lower middle & 174 & April 2009-August 2010 & 2,803 & $217(8)$ & $167(8)$ & $17(5)$ \\
\hline \multicolumn{8}{|l|}{ Sub-Saharan } \\
\hline Rwanda & Low & 12 & $2009-2010$ & 2,552 & $369(15)$ & $273(25)$ & $96(7)$ \\
\hline Kenya & Low & 44 & $2009-2010$ & 15,687 & $1,992(13)$ & $1,030(15)$ & $962(11)$ \\
\hline $\begin{array}{l}\text { Democratic } \\
\text { Republic } \\
\text { of Congo }\end{array}$ & Low & 66 & $\begin{array}{l}\text { January 2009-December } \\
2009\end{array}$ & 1,311 & $249(19)$ & $208(20)$ & $41(16)$ \\
\hline Tanzania & Low & 49 & $2009-2010$ & 1,810 & $154(9)$ & $97(9)$ & $57(8)$ \\
\hline \multicolumn{8}{|l|}{ Asia } \\
\hline India (South) & Lower middle & 1,252 & May 2009-April 2010 & 2,588 & $699(27)$ & $489(35 \%)$ & $210(18 \%)$ \\
\hline $\begin{array}{l}\text { India (Andhra } \\
\text { Pradesh) }\end{array}$ & Lower middle & 1,252 & $\begin{array}{l}\text { May 2009-December } \\
2010\end{array}$ & 6,527 & $1,480(23)$ & NR & NR \\
\hline Bangladesh & Low & 157 & $2009-2010$ & 2,377 & $391(16)$ & 273 (17) & $118(16)$ \\
\hline Bhutan & Lower middle & $<1$ & 2009-2011 & 2,149 & 711 (33) & NR & NR \\
\hline Lao PDR & Lower middle & 7 & $\begin{array}{l}\text { January 2008-December } \\
2010\end{array}$ & $2,338^{*}$ & $523(22)$ & $523(22)$ & NR \\
\hline Philippines & Lower middle & 98 & $\begin{array}{l}\text { January 2009-December } \\
2010\end{array}$ & 5,616 & $1,220(22)$ & $1,068(26)$ & $152(11)$ \\
\hline \multicolumn{8}{|c|}{$\begin{array}{l}\text { Income classification is according to the World Bank. Low income is defined as a per capita gross national income } \leq \$ 1,045 \text {, whereas lower-middle- } \\
\text { income countries are those with a per capita gross national income of }>\$ 1,045 \text { but }<\$ 4,125 \text { [23]. ILI, influenza-like illness; NR, not recorded; PDR, } \\
\text { People's Democratic Republic; pH1N1, } 2009 \text { pandemic H1N1; SARI, severe acute respiratory infection. }\end{array}$} \\
\hline
\end{tabular}

positive for influenza, of which 167 (77\%) presented with ILI and 17 (8\%) with SARI [16]. In contrast to reports from elsewhere in Africa, influenza accounted for a lower percentage of ILI and SARI cases in Nigeria with $8.1 \%$ and $5 \%$, respectively. An overwhelming majority of ILI and SARI occurred in children under 5 (67.8 and 71.6, respectively) concerning for reporting bias or a skewed utilization of healthcare resources. Although individuals presenting with ILI due to pandemic H1N1 were most commonly between the ages of 5 and 17, SARI due to pHIN1 was most frequently detected in individuals over the age of 65 [16]. Seasonality of influenza in Nigeria was less pronounced, but peak influenza activity between 2009 and 2010 occurred during November 2009 and March 2010.

\section{Sub-Saharan Africa}

Influenza is often confused with other febrile illnesses in Sub-Saharan Africa and thus the epidemiology remains poorly defined in this area. Additionally, influenza surveillance in this region has been limited due to financial constraints, limited public health infrastructure, and competing health priorities such as tuberculosis, malaria, and HIV [21].

Rwanda. Rwanda, a Sub-Saharan country of almost 12 million people, initiated an influenza sentinel surveillance program in collaboration with the US Centers for Disease Control and Prevention in 2008 [26]. Between October 2009 and May 2010, the Rwandan National Reference Laboratory tested 2,045 samples from patients meeting the WHO case definition for pandemic H1N1 [22]. Five hundred and thirty-two cases (26\%) tested positive for influenza, 93\% of which were $2009 \mathrm{H} 1 \mathrm{Nl}$. Similar to Morocco, laboratory-confirmed cases of influenza during this pandemic period were highest in children under the age of 15. Overall, the $2009 \mathrm{H} 1 \mathrm{Nl}$ pandemic was reportedly mild in Rwanda with $70 \%$ of cases presenting as ILI and $30 \%$ as SARI. Approximately $12 \%$ of patients required 
hospitalization, of which 69\% received oseltamivir therapy, and there were no deaths reported $[22,27]$. Chronic respiratory problems followed by cardiac disease were the most common comorbid conditions associated with influenza infection in this population [22]. Although influenza was detected year-round in Rwanda, peaks of disease were noted between February/March and October/ November, coinciding with the rainy seasons [27].

Kenya. In 2006, with support from the Centers for Disease Control and Prevention-Kenya, a national sentinel surveillance system was established. Between July 1, 2007, and June 30, 2013, almost 40,000 samples $(0.09 \%$ of Kenya's population) were obtained from patients with ILI and SARI [21]. Influenza was confirmed in 15\% (1,030 of 6,712 ) of patients presenting with ILI and $11 \%$ (962 of 8,975 ) of those admitted with SARI in 2009 to 2010. Less than $3 \%$ of SARI patients were of adult age, which is perhaps due to surveillance bias or a disparity in the utilization of healthcare resources between pediatric and adult populations. Influenza transmission was detected each month; however, peak disease activity was detected between July and November. Influenza vaccination was reported in $1.6 \%$ of patients with ILI and $1.5 \%$ of patients with SARI, highlighting the lack of access to potentially life-saving public health interventions [21].

Democratic Republic of Congo. Beginning in 2007, the Democratic Republic of Congo, home to approximately 67 million people, implemented sentinel surveillance for influenza in the capital Kinshasa in response to the growing threat of avian influenza [28]. In 2009, 1,311 samples were collected from 1,048 patients presenting with ILI and 263 with SARI [17]. Influenza was confirmed in 208 (20\%) of the ILI cases and 41 (16\%) of the SARI cases [17]. Similar to other African countries, cases of SARI peaked in children under the age of 14. Influenza activity appears to circulate most commonly between January and March, but it peaked in October during the $2009 \mathrm{HlNl}$ pandemic [17].

\section{India, Southeast Asia, and Mongolia}

India. In 2004, the Indian Council of Medical Research established a systematic influenza surveillance network to characterize the prevalence and burden of influenza in India, the second most populous country in the world (>1.2 billion people) [29,30]. Between May 2009 and April 2010, 2,588 samples were tested for influenza and 699 (27\%) were positive. The 2009 H1N1 virus accounted for $80 \%$ (557 of 699) of influenza positive infections. Influenza was detected in 35\% of patients presenting with ILI and $18 \%$ of those with SARI in India, which is consistent with other lower-middle-income countries. The 2009 pandemic H1N1 was detected in all ages but peaked in the age range 5 to 15 for those presenting with ILI.

Bangladesh. Bangladesh is a low-income country of 156 million people located east of India that experienced approximately 6,000 2009 H1N1-related deaths with an estimated US $\$ 6.1$ million in direct medical costs $[13,31]$. In collaboration with the government of Bangladesh, the International Centre for Diarrhoeal Disease Research, Bangladesh initiated a hospital-based influenza surveillance network to better characterize the epidemiology of influenza in Bangladesh. From 2009 to 2010, 2,377 samples at the International Centre for Diarrhoeal Disease Research, Bangladesh were collected, 391 (16\%) of which were positive for influenza [13]. Laboratory-confirmed influenza was detected in $17 \%$ and $16 \%$ of patients presenting with ILI and SARI, respectively. Only $1 \%$ of 495 SARI patients over the age of 5 had underlying pulmonary comorbidities compared with $3 \%$ of patients presenting with ILI [13]. Influenza infection was detected each month between May 2008 and September 2010, which is consistent with other tropical countries. The limited access to health care and vaccines in addition to a lack of antiviral drugs and pervasive malnutrition were reported as likely contributors to the increased mortality associated with influenza in Bangladesh.

Bhutan. Bhutan, located just north of Bangladesh and east of India, has a population of approximately 650,000 people and is considered a lower-middle-income country by the World Bank. In collaboration with the Department of Virology, Armed Force Research Institute for Medical Sciences, based in Bangkok, Thailand, Bhutan launched an influenza surveillance system in 2008. Initially, diagnostics were performed in Thailand, as polymerase chain reaction-based domestic influenza diagnostics were not available until April 2010 [14]. Between June 2009 and August 2010, 2,149 samples were collected, 711 (33\%) of which were positive for influenza. Of these, 487 (69\%) were found to be the 2009 pandemic H1Nl virus. As in other low-income to lower-middle-income countries, the most common age group infected with the $2009 \mathrm{HINl}$ virus was 6- to 20 years (57\%) with very few above the age of $50(<2 \%)$. Approximately 22 deaths were attributed to influenza and/or pneumonia during the pandemic; however, none of these had samples obtained for laboratory confirmation, further suggesting that the true burden of influenza in under-resourced areas is unknown due to a lack of standardized diagnostic testing.

Lao People's Democratic Republic. Influenza-like illness accounts for a significant proportion (50,390 of 509,313 or $10 \%$ ) of all outpatient and emergency room visits in Lao People's Democratic Republic (PDR) from 2008 to 2010 [32]. Lao PDR is a lower-middle-income country of 6.7 million people located in between Thailand and Vietnam [33]. The Lao PDR national influenza surveillance network was established in response to emerging strains of influenza, including the $\mathrm{H} 5 \mathrm{N1}$ avian strain and the $2009 \mathrm{H} 1 \mathrm{Nl}$ pandemic virus. Between 2008 and 2010, 523 cases (22\%) of influenza were confirmed in 2,338 patients presenting with ILI. Influenza activity was 
highest in children between the ages of 5 and 17 (33\%) followed by those 18 to 64 (28\%). Strangely, influenza was not detected in the 19 individuals older than 65 years of age that were tested. Although Lao PDR crosses both tropical and semitropical zones, influenza was detected year-round typically and displayed peak activity between August and November. Similar to most under-resourced areas, seasonal and pandemic influenza vaccines are not routinely available.

Philippines. The Philippines is an archipelago that is home to over 98 million people and located north east of Malaysia [34]. Since 2004, the Research Institute for Tropical Medicine has established the National Influenza Center in the Philippines, which consists of 2 sentinel sites in 12 of the 17 administrative regions. Of the 4,178 respiratory samples collected from patients with ILI between January 2009 and December 2010, 1,068 (26\%) were positive for influenza, $48 \%$ of which were pandemic H1N1 [35]. Although the seasonal strains of $\mathrm{H} 1 \mathrm{~N} 1$ and $\mathrm{H} 3 \mathrm{~N} 2$ more commonly occurred in children under 5, the 2009 pandemic H1N1 predominantly infected individuals between the ages of 5 and 14. Between April 2009 and December 2011, 1,438 patients were admitted with SARI and 152 (11\%) were confirmed to have been infected with influenza. Similar to other tropical countries, influenza was detected year-round but appeared to peak from February to March and June to September, coinciding with the rainy season.

Mongolia. The increased burden of influenza in resourcelimited areas is not geographically isolated to Africa, India, or Southeast Asia. Although the first case of $2009 \mathrm{HlNl}$ pandemic influenza did not occur in Mongolia until October 2009, a community-based serological study in the Selenghe province suggests that once introduced, this virus infected approximately 30\% of the Mongolian population during the first wave of the pandemic. The low population density of Mongolia, in comparison to more developed or urban nations, may explain the late appearance of this global pathogen. More than one-half of the influenza infections during this period occurred in individuals under 20 years of age [36]. Although influenza is often a vaccine-preventable illness, $93.9 \%$ of patients in this study did not receive an influenza seasonal vaccine in the previous year. Unfortunately, the $2009 \mathrm{H} 1 \mathrm{Nl}$ pandemic vaccine was not available prior to January 2010, highlighting the limited access to public health preventative strategies.

\section{PANDEMIC H1N1 MORTALITY}

Influenza infection results in a substantial burden of illness in resource-limited settings and is the etiology of 5\% to $27 \%$ of all cases of SARI (Table 1). Mortality attributable to influenza in these settings is difficult to determine as case fatality rates in many of these countries are not regularly reported. The lack of epidemiologic data surrounding influenza-associated mortality in low-income countries is highlighted by the fact that although Africa and Southeast
Asia account for $38 \%$ of the world's population, only $12 \%$ of the $2009 \mathrm{HlNl}$ deaths were reported from these regions. Limited studies from low-income and low-middleincome countries, such as those from India and Kenya, demonstrate markedly elevated influenza-related mortality rates in hospitalized patients ranging from $4 \%$ to $68 \%$ (Table 2) [37-45]. Additionally, a recent meta-analysis of the global burden of severe influenza in pediatric populations reported that $99 \%$ of SARI cases in children younger than 5 occur in low-income and middle-income countries, $13 \%$ of which are due to influenza $[46,47]$.

Modeling studies have estimated a disproportionate burden of influenza in resource-limited settings. Using data derived from symptomatic attack rates and case fatality rates modified by a respiratory disease-related mortality multiplier, Dawood et al. [48] found that an estimated 201,200 $(105,700$ to 395,600$)$ respiratory-related deaths associated with $2009 \mathrm{H} 1 \mathrm{Nl}$ influenza occurred globally. This is more than 15 times the reported number of laboratory deaths from the $2009 \mathrm{HlNl}$ provided to WHO. Furthermore, 51\% of these deaths were estimated to have occurred in Africa and Southeast Asia with an estimated 2.4-fold increase in mortality in Africa and a 1.4-fold increase in Southeast Asia compared with resource-rich countries; the true burden of global influenza appears to reside in the most impoverished and under-resourced nations $[10,48]$.

These estimates were supported by the GLaMOR (Global Pandemic Mortality) study, which used global and regional estimates of pandemic H1Nl influenza deaths to also highlight the disproportionate burden of influenza morbidity and mortality in resource-limited settings. The GLaMOR study, however, found differences in the regional distribution of influenza-related mortality compared with the aforementioned modeling study. Whereas the highest mortality rates were estimated to occur in the Americas by the GLaMOR study, Dawood et al. [48] projected the greatest mortality in Africa, India, and Southeast Asia. Importantly, neither study had reliable influenza-related mortality data from Africa. In the case of the GLaMOR study, data was derived from South Africa, an upper-middle-income country that is vastly different from many other African countries in terms of access to and quality of health care [49]. In contrast, Dawood et al. [48] based their conclusions of increased influenza-related mortality in Africa, India, and Southeast Asia on increased respiratory-related mortality multipliers proportional to case fatality rates from all respiratory-related illness in these areas. Though this variance in regional burden of disease underscores the deficient epidemiology, it supports the growing understanding of the disproportionate burden of influenza-associated morbidity and mortality in resource-constrained environments.

\section{SPECIFIC RISK FACTORS FOR SEVERE INFLUENZA IN RESOURCE-LIMITED SETTINGS}

Since the start of the $2009 \mathrm{H} 1 \mathrm{Nl}$ pandemic, WHO and member states have collected patient information in an 
TABLE 2. Mortality of hospitalized patients with influenza in low and lower-middle-income countries during the first year of the 2009 H1N1 pandemic

\begin{tabular}{|lllrr|}
\hline Country (Region) & Income Level & Date of Surveillance & Hospitalized, $\mathrm{n}$ & Case Fatality Rate, \% \\
\hline India (South) & Lower middle & May 2009-April 2010 & 50 & 68 \\
India & Lower middle & May 2009-April 2010 & 54 & 36 \\
India (Jodhpur Rajasthan) & Lower middle & 2009-2010 & 221 & 88 \\
India (Kerala) & Lower middle & June 2009-December 2011 & 274 & 25 \\
India (Saurashtra) & Lower middle & September 2009-February 2010 & 25 \\
India & Lower middle & August 2009-April 2010 & 1,480 \\
India (Andhra Pradesh) & Lower middle & 2009-2010 & 63 \\
India (Western) & Lower middle & August 2009-February 2010 & 88 \\
Kenya & Low & June 2009-November 2009 & 22 \\
\hline Income level defined by World Bank definitions [23]. & & 4 \\
\hline
\end{tabular}

attempt to understand which conditions predispose influenza-infected patients to severe outcomes. Data from 70,000 patients hospitalized in 19 countries or administrative regions with $\mathrm{H} 1 \mathrm{Nl}$ influenza revealed that age, cardiorespiratory disease, diabetes, and pregnancy are leading risk factors associated with severe disease [50]. Despite the low level of infection seen in developed countries among older adults, mortality was highest among those 50 to 64 years old and over 65 (relative risk $[R R]=1.5$ and 1.6, respectively, compared with the general population) [50]. Only 1 country (Madagascar) was defined as low income; the rest were among upper-middle-income and high-income countries including Argentina, Australia, Canada, Chile, China, France, Germany, Hong Kong SAR, Japan, Mexico, the Netherlands, New Zealand, Singapore, South Africa, Spain, Thailand, the United States, and the United Kingdom. Recent studies have identified other risk factors that may be playing a role in predisposing individuals from low-income countries to more severe disease such as HIV and malnutrition [51].

Cardiopulmonary comorbidities in particular have been associated with poor outcomes especially in resourceconstrained environments. Patients with more severe influenza including viral pneumonia were more likely to have underlying cardiac disease. In Morocco, cardiovascular comorbidities, including hypertension, were associated with an increased risk of death with an adjusted odds ratio of 28.2 (95\% confidence interval [CI]: 2 to 398.7; $\mathrm{p}=0.013)[20,52,53]$. Cardiac disease was also identified as a leading risk factor for intensive care unit (ICU) admission and death from influenza, with an RR of 8 for severe disease in India $[41,50]$.

Chronic infections such as tuberculosis and HIV, more prevalent in low-income settings, are also associated with severe disease. In South Africa, individuals with HIV accounted for $20 \%$ of deaths due to $2009 \mathrm{H} 1 \mathrm{Nl}$ pandemic influenza, which is notably higher than the $10 \%$ HIV prevalence in the general population [54]. After controlling for age, influenza infection of HIV-positive individuals was noted to carry a 5-fold risk of SARI (RR $=5.3 ; 95 \% \mathrm{CI}: 4$ to 6.9) compared with HIV-negative individuals [55-57]. The increased association between HIV infection and severe influenza disease was greatest in the adults between the ages of 25 and 44 [57]. HIV-infected individuals were also noted to have increased rates of bacterial coinfection (58\%) compared with HIV-negative patients (44\%), whereas only $10 \%$ to $30 \%$ of hospitalized patients in Argentina or the United States were found to have bacterial coinfection [58-60].

Malnutrition has long been suspected of predisposing individuals to infection through its role in affecting the immune response, but studies have provided conflicting results. Both micro- and macronutrient deficiency have been implicated in the development of immunodeficiency in general and specifically in increasing the susceptibility to influenza in animal models $[61,62]$. Additionally, malnutrition was associated with a poor response to influenza vaccination in 1 study of elderly adults [63]. Yet, another study among pediatric patients found no association between malnutrition and influenza [64]. Given the conflicting results, absence of sufficient data, and the fact that 95.9\% of the 826 million undernourished people live in resource-limited settings globally, the role of malnutrition as a risk factor for severe influenza requires further investigation [65].

\section{INFLUENZA-ASSOCIATED SEVERE DISEASE}

\section{Respiratory complications of influenza}

Influenza infection typically results in a mild, self-limiting upper respiratory tract infection with fever, cough, sore throat, myalgia, rhinorrhea, conjunctivitis, and shortness of breath. Severe influenza, defined by more severe organ involvement or complications, is most commonly associated with pulmonary complications including primary viral pneumonia, secondary bacterial infection, and exacerbations of underlying lung disease, and it is more often seen in older adults or those with other high-risk conditions [66]. Additionally, influenza can progress to acute respiratory distress syndrome (ARDS). Influenza infects respiratory epithelial cells, including alveolar epithelial cells, resulting in flooding of the alveolar lumen with protein-rich fluid, blood, and 
TABLE 3. Intensive care unit demographics, therapies, and outcomes in lower-middle, upper-middle, and high-income levels

\begin{tabular}{|c|c|c|c|c|c|c|c|c|c|c|c|c|c|c|}
\hline Country & Income Level & Study Date & $\begin{array}{c}\text { Patients, } \\
n\end{array}$ & $\begin{array}{l}\text { Women, } \\
\text { n (\%) }\end{array}$ & $\begin{array}{l}\text { ARDS, } \\
\text { n (\%) }\end{array}$ & $\begin{array}{c}\text { Mechanical } \\
\text { Ventilator, } \\
\text { n (\%) }\end{array}$ & $\begin{array}{c}\text { Vaso- } \\
\text { pressors, } \\
\text { n (\%) }\end{array}$ & $\begin{array}{c}\text { Paralysis, } \\
\text { n (\%) }\end{array}$ & $\begin{array}{l}\text { Prone, } \\
\text { n (\%) }\end{array}$ & $\begin{array}{l}\text { HFOV, } \\
\text { n (\%) }\end{array}$ & $\begin{array}{l}\text { ECMO, } \\
\text { n (\%) }\end{array}$ & SOFA & $\begin{array}{c}\text { APACHE } \\
\text { II }\end{array}$ & $\begin{array}{c}\text { Mortality, } \\
\text { n (\%) }\end{array}$ \\
\hline India & Lower middle & $\begin{array}{r}\text { September 2009- } \\
\text { December } 2009\end{array}$ & 106 & $64(60)$ & $85(80)$ & $18(17)$ & NR & $62(59)$ & NR & NR & NR & 5.5 & 14.4 & (49) \\
\hline Syria & Lower middle & 2009 & 80 & $32(40)$ & $58(73)^{*}$ & $59(74)$ & NR & $47(80)$ & NR & NR & NR & 5 & 15.2 & (51) \\
\hline Mexico & Upper middle & 2009 & 58 & 31 (53) & NR & $48(82.7)$ & 34 (59) & NR & $4(7)$ & $1(2)$ & 0 & 9 & 20.1 & $20(35)$ \\
\hline Tunisia & Upper middle & $\begin{array}{c}\text { November 2009- } \\
\text { January } 2010\end{array}$ & 32 & $14(44)$ & $21(34)$ & 15 (46.9) & $7(22)$ & NR & NR & NR & NR & 4 & NR & $9(28)$ \\
\hline South Korea & High & $\begin{array}{c}\text { September 2009- } \\
\text { February } 2010\end{array}$ & 245 & $111(45)$ & $136(56)$ & $162(66.1)$ & $88(36)$ & $106(43)$ & $21(9)$ & NR & $12(5)$ & 7.7 & 19.1 & $80(33)$ \\
\hline Ireland & High & $\begin{array}{l}\text { July 2009-June } \\
2010\end{array}$ & 77 & 37 (49) & $47(62)$ & $50(64.9)$ & $39(51)$ & NR & NR & $17(22)$ & $4(7)$ & 5.9 & NR & $14(18)$ \\
\hline Canada & High & 2009 & 168 & $113(67)$ & 73 & $128(76.2)$ & $55(33)$ & $47(28)$ & $5(3)$ & $10(12)$ & $7(4)$ & 6.8 & 19.7 & $29(17)$ \\
\hline $\begin{array}{l}\text { Australia/ } \\
\qquad \begin{array}{l}\text { New } \\
\text { Zealand }\end{array}\end{array}$ & High & 2009 & 722 & $376(52)$ & $336(49)$ & 64.60 & NR & NR & NR & NR & $53 / 706(8)$ & NR & NR & 103 (14) \\
\hline $\begin{array}{l}\text { United } \\
\text { States }\end{array}$ & High & 2009 & 154 & $23(50)$ & $48(38)$ & 58 & NR & NR & NR & NR & NR & NR & NR & $37(24)$ \\
\hline $\begin{array}{l}\text { United } \\
\text { States }\end{array}$ & High & May-June 2009 & 47 & $27(57)$ & $30(64)$ & NR & NR & NR & NR & NR & NR & 7 & 21 & $8(17)$ \\
\hline $\begin{array}{l}\text { Upper-middle } \\
>\$ 12,746[23] \\
\text { distress syndro } \\
{ }^{*} \mathrm{ALI} \text { or ARDS. }\end{array}$ & $\begin{array}{l}\text { income countri } \\
\text { ome; Income levels } \\
\text { omO, ext }\end{array}$ & $\begin{array}{l}\text { es are those with a pe } \\
\text { were determined by } t \\
\text { racorporeal membrane }\end{array}$ & $\begin{array}{l}\text { r capita gr } \\
\text { he World } \\
\text { oxygenat }\end{array}$ & $\begin{array}{l}\text { oss natior } \\
\text { 3ank [23]. } \\
\text { on; HFOV }\end{array}$ & $\begin{array}{l}\text { Al income } \\
\text { ALI, acute I } \\
\text { high-frequ }\end{array}$ & $\begin{array}{l}>\$ 4,125 \text { b } \\
\text { ng injury; A } \\
\text { ncy oscillato }\end{array}$ & $\begin{array}{l}<\$ 12,74 \\
\mathrm{CHE} I \mathrm{I}, \mathrm{Ac} \\
\text { ventilati }\end{array}$ & $\begin{array}{l}\text { and high } \\
\text { e Physio } \\
\text { NR, not }\end{array}$ & $\begin{array}{l}\text { come } \\
\text { y an } \\
\text { cord }\end{array}$ & $\begin{array}{l}\text { untries } \\
\text { aronic H } \\
\text { OFA, Se }\end{array}$ & $\begin{array}{l}\text { have per } \\
\text { fealth Eval } \\
\text { equential }\end{array}$ & $\begin{array}{l}\text { ta } \\
\text { on; } \\
\mathrm{nF}\end{array}$ & $\begin{array}{l}\text { s natio } \\
\text { DS, act } \\
\text { e Asse }\end{array}$ & $\begin{array}{l}\text { I income of } \\
\text { respiratory } \\
\text { ment Score }\end{array}$ \\
\hline
\end{tabular}

inflammatory cells, limiting oxygen gas exchange and resulting in severe hypoxic respiratory failure. The pathogenesis of influenza-induced ARDS has been reviewed previously [67]. The 2009 pandemic H1N1 virus led to ARDS in $30 \%$ to $80 \%$ of patients admitted to an ICU with increased percentages associated with lower-income countries (Table 3) [11,43,58,59,68-73].

Bacterial coinfection was first recognized as a major complication of influenza during the 1918 epidemic that resulted in the death of over 50 million individuals. Autopsy reports suggest that close to $95 \%$ of severe illness and death were associated with bacterial coinfection [74]. Infection with the $2009 \mathrm{H} 1 \mathrm{~N} 1$ pandemic strain was also associated with secondary bacterial infection in approximately $20 \%$ to $40 \%$ of ICU patients in most studies (Table 3) $[58,59,68]$. The pathogenesis underlying influenza-bacterial coinfection is likely multifactorial and involves changes to both the airway defense, including decreased mechanical clearance of invading bacteria through deficient ciliary movement, and breakdown of the airway epithelium. Epithelial damage from influenza infection is thought to be an important step in the pathogenesis of secondary bacterial pneumonia by facilitating bacterial adherence [75]. Additionally, influenza-associated depletion of alveolar macrophages and alterations to the innate immune response reduces the ability to fight invading bacteria.

\section{Cardiovascular complications of influenza}

Although influenza is traditionally associated with respiratory complications, cardiac sequelae are increasingly recognized. In fact, an additional 83,300 (range 46,000 to 179,900) cardiovascular-related deaths worldwide have been attributed to infection with the 2009 pandemic H1N1 virus, suggesting that the already substantial global mortality burden of influenza is likely underestimated due to unrecognized cardiopulmonary complications in influenzainfected individuals worldwide [48].

The relationship between influenza and increased cardiac morbidity and mortality was initially recognized in epidemiologic studies demonstrating peaks of influenza activity and cardiac-related deaths coinciding during winter months [76]. Increases in cardiovascular deaths during influenza epidemics further suggest an influenza-specific causal association. The cardiovascular complications of influenza range from asymptomatic electrocardiogram abnormalities to acute myocardial infarction. In a study of 30 adults with clinical evidence of influenza infection, $53 \%$ had abnormal electrocardiograms on day 1 and $23 \%$ on day 11 , although serum troponin levels and echocardiographic studies were unremarkable [77]. More severely, 15\% of influenza-infected army recruits had evidence of myocarditis with increased levels of cardiac enzymes and echocardiographic evidence of wall motion abnormalities [78].

More recently, studies have demonstrated myocardial dysfunction during infection with the $2009 \mathrm{H} 1 \mathrm{Nl}$ pandemic influenza virus. An echocardiographic study of 28 patients presenting with ILI to a hospital in Turkey revealed a global myocardial performance index (sum of isovolumetric contraction time and isovolumetric relaxation time divided by ejection time; higher values correspond to increased 
cardiac dysfunction) that was significantly higher in 2009 H1N1-infected patients as compared to patients with non-influenza-related ILI [79]. Similarly, a Belgian study using echocardiography to evaluate the incidence and hemodynamic consequences of right and left ventricular dysfunction in critically ill patients with $2009 \mathrm{H} 1 \mathrm{N1}$ infection found that $72 \%$ of the 39 patients evaluated displayed abnormal ventricular function; $46 \%(n=13)$ had isolated left ventricular dysfunction, 39\% ( $n=11)$ had isolated right ventricular abnormalities, and $14 \%(n=4)$ had biventricular dysfunction [80]. Interestingly, whereas left ventricular function normalized after an initial decline, right ventricular abnormalities tended to worsen over the course of illness.

Influenza infection has also been associated with acute myocardial infarction [81,82]. The most compelling evidence comes from influenza vaccination trials, which demonstrate a $67 \%$ reduction in the risk of myocardial infarction and a decrease in cardiovascular mortality from $8 \%$ in unvaccinated subjects to $2 \%$ among the vaccinated $(\mathrm{RR}=0.25 ; 95 \% \mathrm{CI}: 0.07$ to $0.86 ; \mathrm{p}=0.01)[83,84]$. The protective effect of influenza vaccines has been most pronounced in older adults with a 19\% reduced risk of hospitalization for heart disease, 23\% reduction in cerebrovascular accidents, and a 50\% reduction in all-cause mortality during influenza seasons $[85,86]$. Additionally, a recent meta-analysis found that influenza vaccination was associated with a lower risk of composite cardiovascular events (RR $=.64 ; 95 \% \mathrm{CI}: 0.48$ to $0.86 ; \mathrm{p}=0.003$ ) [87]. Despite the current recommendation for patients with underlying cardiovascular disease to receive influenza vaccination coverage, coverage remains insufficient in the resource-rich settings globally; in resource-limited environments, vaccines are very rarely available at all [88].

\section{H1N1 ICU care and outcomes}

Severe influenza requiring ICU admission is associated with significant morbidity and mortality. In the United States between April 2009 and April 2010, an estimated 61 million people were infected with the $2009 \mathrm{H} 1 \mathrm{Nl}$ virus, resulting in over 250,000 hospitalizations and 12,500 deaths [72]. An estimated 23\% to 34\% of hospitalized patients required admission to an ICU [72]. Even though ICU admissions globally are associated with underlying comorbidities, pregnancy, and/or a delay in antiviral therapy, very little is known about critical care management and outcomes in resource-limited settings. Recent studies from India and Syria suggest that influenza-related critical illness in low-income countries is associated with substantially greater mortality than in high-income countries (Table 3).

A multicenter study from 3 ICU in South India reported 106 (106 of 464; 22.8\%) patients with $2009 \mathrm{H1Nl}$ required admission to an ICU [43]. Of these, 18 (17\%) required invasive mechanical ventilation and 16 (15.1\%) needed dialysis. ICU mortality in South India was reported as $49 \%$. Despite lower severity of illness scores (APACHE II
[Acute Physiology and Chronic Health Evaluation] or SOFA [Sequential Organ Failure Assessment] scores where higher scores are worse) among these patients, this ICU case fatality rate is approximately 2 -fold to 3-fold higher than that reported in ICU in the United States, Canada, New Zealand, or Australia (Table 3) [59].

Outcomes in ICU located in Syria were also worse than in high-resource areas. In a retrospective review of $80 \mathrm{pa}$ tients admitted to 4 ICU in Damascus, Syria, 58 (72.5\%) had acute lung injury or ARDS and 59 (73.7\%) were mechanically ventilated [68]. APACHE II and SOFA scores reported in Syria were similar to those in South India (15.2 and 5 , respectively), and ICU mortality was similarly elevated at $51 \%$ [43].

As suggested by the data in Syria and India, despite markedly lower SOFA and APACHE II scores in resourcelimited countries, there is higher mortality in these settings (Table 3) $[43,68]$. Furthermore, mortality rates from ICU in upper-middle-income countries, including Mexico and Tunisia, suggest that resource availability is linked to outcomes in severe disease there as well. Mortality rates in both countries were between those from lower-income and higher-income countries (Table 3) [11,43,58,59,68-73]. Disparities in access to critical care resources may partly explain some of the pandemic influenza mortality differences reported among high-income and low-income countries. However, additional factors such as lack of available trained staff, or even travel time to facilities, cost of treatment for patients and families, and delays in presentation likely also contribute. For example, a recent study showed that patients presenting to ICU in India arrived on average 6 days after the onset of symptoms versus patients in high-income countries who presented 3 to 4 days after [43].

\section{Disparity in access to treatment in resource- constrained areas}

The $2009 \mathrm{H} 1 \mathrm{~N} 1$ influenza pandemic revealed the limitations of current critical care capacity in all countries but no more so than in resource-limited regions. Notable barriers to treatment in resource-constrained locations included lack of influenza diagnostics, vaccinations, antiviral medications, and even basic monitoring devices such as blood pressure cuffs or pulse oximeters. Additionally, many countries lacked basic supportive treatment such as oxygen let alone more advanced critical care support, such as mechanical ventilation or cardiopulmonary monitoring $[89,90]$.

Influenza vaccination remains the best defense against seasonal influenza and may play a role in reducing the severity of disease $[91,92]$. Unfortunately, the populations in low-income countries, which bear a disproportionate burden of disease, are least likely to have access to vaccination. In a 2012 survey of 14 African countries, only 4 (29\%) reported availability of seasonal influenza vaccines [93]. However, within these countries, $<2 \%$ of the 
population that had access were actually vaccinated. Reports from Morocco, Mongolia, Kenya, and Lao PDR suggest a similar deficiency in seasonal vaccine coverage with only $2 \%$ to $6 \%$ of the population being vaccinated $[20,21,32,36]$. Although data supporting vaccine efficacy in low-income areas are limited, a recent prospective controlled trial of maternal influenza immunization in Bangladesh demonstrated not only reliable immunogenicity of the inactivated vaccine in pregnant women but also decreased infection in their newborn children [94-96].

Antiviral neuraminidase inhibitors (NAI) are the mainstay of pharmacological treatment for influenza; the principal NAI used is oseltamivir. Access to antivirals, however, has been identified as a major barrier to delivery of effective care in resource-poor environments, due to poor availability or high cost. Data from Argentina demonstrated an increased severity of disease in patients who received antiviral therapy $>48 \mathrm{~h}$ from the onset of symptoms compared with those treated earlier, including increased risk of pneumonia ( $66.6 \%$ vs. $33.3 \%$; $p=0.006)$, ICU admission ( $68 \%$ vs. $32 \%$; $p=0.01$ ), prolonged hospitalization (11 vs. 7 days), need for oxygen (61.7\% vs. $38.2 \% ; p=0.0001)$, and mechanical ventilation (68.2\% vs. $31.8 \% ; p=0.002)$ [54]. In a survey of 40 countries about the availability of NAI, only $65 \%$ of respondents (19 of 31) reported these drugs as being available [93].

Early initiation of antiviral therapy correlates with improved outcomes; however, there are significant disparities in the dispensing of these drugs [97]. The increased use of NAI in Japan correlated with decreased mortality ( 0.15 per 100,000 people) in contrast to the conservative distribution in Argentina, which experienced higher mortality rates (1.73 per 100,000) [98]. Recently, a study demonstrated a $1.6 \%$ reduction of H1N1 mortality with each $10 \%$ increase in kilograms of oseltamivir distributed [98]. Although the use of and timing of NAI in ICU found in low-income countries was not regularly reported, it is worth noting that only $29 \%$ to $43 \%$ of patients admitted to ICU in high-income countries received NAI within $48 \mathrm{~h}$ of symptom onset $[71,72]$. Improved education and awareness of the efficacy and protocols for NAI may help. Early initiation of antiviral therapy was reported to have improved in Ukraine following a WHO mission there, suggesting that real-time WHO guidance can affect clinical management in the middle of a pandemic [54].

Supportive care including mechanical ventilation, cardiopulmonary monitoring, and other invasive support is essential in the management of critically ill influenza patients. Mechanical ventilation was required by approximately $40 \%$ to $80 \%$ of patients admitted to an ICU in both low-income and high-income countries (Table 3) [11,43,58,59,68-73]. However, many resource-constrained environments lack ICU capabilities. Moreover, even many upper-middle-income countries have limited healthcare infrastructure, which can be quickly overwhelmed and unable to meet the surge demand of a pandemic; in these cases, such as in Mexico, critically ill patients may be managed outside of ICU [11]. Similar strains on resources have been identified in Chile where critical care beds and mechanical ventilators were identified as limited resources [99]. Possible solutions may be to develop experienced referral centers where outcomes of patients with ARDS are improved; regionalizing critical care services may improve outcomes in pandemic disease especially in areas where these resources are already limited [100].

A significant number of patients in high-income countries receive salvage oxygenation therapies including prone positioning, extracorporeal membrane oxygenation (ECMO), and/or neuromuscular blockade for severe influenza; these therapies require experience and expertise that likely contributes to the disparity in mortality between resource-rich and resource-poor countries. Use of prone positioning may be a viable option for severe lung injury and/or ARDS resulting from influenza in resource-limited countries given that expensive technology is not required. Prone positioning has been shown to improve oxygenation and, more recently, mortality in patients with severe ARDS [101]. It was reported as used in 3\% to $8 \%$ of critically ill patients in South Korea and the Canada $[59,71,101]$. In Mexico, a more resourcechallenged country, prone position was implemented in $6.9 \%$ of patients admitted to ICU in Mexico (Table 3) [11]. Prone positioning has not been mentioned in any reports from resource-limited countries, but should be considered as inexpensive salvage therapy with appropriate education and training for patients with refractory hypoxia. The use of ECMO has increased in many ICU settings following improved outcomes documented in the 2009 CESAR (Conventional Ventilation or ECMO for Severe Adult Respiratory Failure) trial. Approximately 4\% to $7 \%$ of patients in highincome countries were treated with the use of ECMO [75]. There are no reported cases of use in low-income countries. Neuromuscular paralysis has been reported in Syria and India where its use is more frequent ( $58.5 \%$ to $79.7 \%$ ) than in highincome countries such as South Korea and Canada (28\% to $43 \%$ ); this may indicate both a need for and a lack of available rescue oxygenation modalities in such settings (Table 3 ) $[43,59,68,71]$.

Precluding even advanced technology, some resourcelimited countries report a lack of even basic supportive treatments including, for example, oxygen [69]. Oxygen is considered an essential medicine by WHO and is on WHO's essential medicines list to guide resource-limited countries on a basic formulary. Pulse oximeters and appropriate use of oxygen therapy can reduce mortality in resource-limited environments [102]. However, despite this priority, it has been cited as "never available" in 11\% of hospitals in lowincome and middle-income countries [90]. Similarly, in hospitals that reported having oxygen, it was "sometimes available" $33 \%$ of the time and only "always available" $21 \%$ of the time [90]. Oxygen availability in Sub-Saharan Africa represents a significant challenge; whereas 44\% (99 of 231) of health facilities in 12 Sub-Saharan countries surveyed in a 2007 to 2009 study reported access to oxygen, only 34\% (75 
of 231) reported access to relevant, needed supplies such as face masks or tubing [89].

\section{SUMMARY}

The first pandemic of the 21st century, $2009 \mathrm{H} 1 \mathrm{N1}$, exposed significant gaps in the current understanding of the global burden of influenza. Lack of robust influenza epidemiology in the world's most populous and underresourced regions heralds a major deficiency in our understanding of the true burden of influenza. Though this burden remains poorly characterized and underestimated, there is growing recognition that resource-limited countries bear a disproportionate burden of morbidity and mortality from influenza globally. The difference in mortality between high-resource and low-resource countries is likely attributable in part to the increased prevalence of underlying highrisk comorbidities such as untreated cardiopulmonary disease, HIV, and malnutrition, as well as limited availability of antivirals, vaccines, and or supportive care resources such as oxygen, mechanical ventilators, and salvage technologies such as ECMO. Influenza is a preventable and treatable cause of severe respiratory illness but resources that exist in high-income countries will need to reach patients in resource-limited countries where the burden is highest. Hopefully, improved epidemiology of influenza can help further guide allocation of preventative and supportive interventions such as vaccines, antiviral medications, and improved basic health care in order to mitigate the impact of influenza infection on these most vulnerable populations.

\section{REFERENCES}

1. WHO. Vaccines against influenza WHO position paper-November 2012. Wkly Epidemiol Rec 2012;87:461-76.

2. Centers for Disease Control and Prevention. Overview of Influenza Surveillance in the United States. 2014. Available at: http://www. cdc.gov/flu/weekly/overview.htm. Accessed July 25, 2014.

3. World Health Organization. WHO Surveillance Case Definitions for ILI and SARI. January 2014. Available at: http://www.who.int/influenza/ surveillance_monitoring/ili_sari_surveillance_case_definition/en/. Accessed July 25, 2014.

4. Taubenberger JK, Morens DM. 1918 Influenza: the mother of all pandemics. Emerg Infect Dis 2006;12:15-22.

5. Mei Z, Lu S, Wu X, et al. Avian influenza A (H7N9) virus infections, Shanghai, China. Emerg Infect Dis 2013;19:1179-81.

6. Centers for Disease Control and Prevention. Highly Pathogenic Avian Influenza A (H5N1) in People. 2014. Available at: http://www. cdc.gov/flu/avianflu/h5n1-people.htm. Accessed July 26, 2014.

7. Stohr K. The global agenda on influenza surveillance and control. Vaccine 2003;21:1744-8.

8. Girard MP, Tam JS, Assossou OM, Kieny MP. The 2009 A (H1N1) influenza virus pandemic: a review. Vaccine 2010;28:4895-902.

9. Bautista E, Chotpitayasunondh $T$, Gao Z, et al. for the Writing Committee of the WHO Consultation on Clinical Aspects of Pandemic (H1N1) 2009 Influenza. Clinical aspects of pandemic 2009 influenza A (H1N1) virus infection. N Engl J Med 2010;362:1708-19.

10. García-Basteiro AL, Llupià A, Mena G, Bayas JM, Trilla A. Quantifying the efficacy of influenza vaccines. Lancet Infect Dis 2012;12:657-8; author reply 660-1.

11. Domínguez-Cherit $G$, Lapinsky $S E$, Macias $A E$, et al. Critically ill patients with 2009 influenza $A(H 1 N 1)$ in Mexico. JAMA 2009;302: 1880-7.
12. Viboud C, Simonsen L. Global mortality of 2009 pandemic influenza A H1N1. Lancet Infect Dis 2012;12:651-3.

13. Azziz-Baumgartner E, Alamgir AS, Rahman M, et al. Incidence of influenza-like illness and severe acute respiratory infection during three influenza seasons in Bangladesh, 2008-2010. Bull World Health Organ 2012;90:12-9.

14. Wangchuk $S$, Thapa $B$, Zangmo $S$, Jarman RG, Bhoomiboonchoo $P$, Gibbons RV. Influenza surveillance from November 2008 to 2011; including pandemic influenza A(H1N1)pdm09 in Bhutan. Influenza Other Respir Viruses 2013;7:426-30.

15. Barakat A, Ihazmad H, El Falaki F, Tempia S, Cherkaoui I, El Aouad R. 2009 Pandemic influenza A virus subtype H1N1 in Morocco, 2009-2010: epidemiology, transmissibility, and factors associated with fatal cases. J Infect Dis 2012;206(Suppl 1):S94-100.

16. Dalhatu IT, Medina-Marino A, Olsen SJ, et al. Influenza viruses in Nigeria, 2009-2010: results from the first 17 months of a national influenza sentinel surveillance system. J Infect Dis 2012;206(Suppl 1): S121-8.

17. Muyembe Tamfum JJ, Nkwembe E, Bi Shamamba SK, et al. Sentinel surveillance for influenza-like illness, severe acute respiratory illness, and laboratory-confirmed influenza in Kinshasa, Democratic Republic of Congo, 2009-2011. J Infect Dis 2012;206(Suppl 1):S36-40.

18. Nzussouo NT, Michalove J, Diop OM, et al. Delayed 2009 pandemic influenza A virus subtype H1N1 circulation in West Africa, May 2009-April 2010. J Infect Dis 2012;206(Suppl 1):S101-7.

19. Radin JM, Katz MA, Tempia S, et al. Influenza surveillance in 15 countries in Africa, 2006-2010. J Infect Dis 2012;206(Suppl 1): S14-21.

20. Barakat $A$, Ihazmad $H$, Benkaroum $S$, et al. Influenza surveillance among outpatients and inpatients in Morocco, 1996-2009. Plos One 2011;6:e24579.

21. Katz MA, Muthoka P, Emukule GO, et al. Results from the first six years of national sentinel surveillance for influenza in Kenya, July 2007-June 2013. PloS One 2014;9:e98615.

22. Wane J, Nyatanyi T, Nkunda R, et al. 2009 pandemic influenza $A$ (H1N1) virus outbreak and response-Rwanda, October, 2009-May, 2010. Plos One 2012;7:e31572.

23. The World Bank. Country and Lending Groups; Data 2014. Available at: http://data.worldbank.org/about/country-and-lending-groups. Accessed July 29, 2014.

24. The World Bank. Morocco 2014 [data]. Available at: http://www. worldbank.org/en/country/morocco. Accessed July 28, 2014.

25. The World Bank. Nigeria 2014 [data]. Available at: http://data. worldbank.org/country/nigeria. Accessed July 28, 2014.

26. The World Bank. Rwanda 2014 [data]. Available at: http://data. worldbank.org/country/rwanda. Accessed July 28, 2014.

27. Nyatanyi T, Nkunda R, Rukelibuga J, et al. Influenza sentinel surveillance in Rwanda, 2008-2010. J Infect Dis 2012;206(Suppl 1): S74-9.

28. The World Bank. Democratic Republic of Congo 2014 [data]. Available at: http://data.worldbank.org/country/congo-dem-rep. Accessed July 28, 2014.

29. Chadha MS, Broor S, Gunasekaran P, et al. Multisite virological influenza surveillance in India: 2004-2008. Influenza Other Respir Viruses 2012;6:196-203.

30. The World Bank. India 2014 [data]. Available at: http://data. worldbank.org/country/india. Accessed July 28, 2014.

31. The World Bank. Bangladesh 2014 [data]. Available at: http://data. worldbank.org/country/bangladesh. Accessed July 28, 2014.

32. Khamphaphongphane $B$, Ketmayoon $P$, Lewis HC, et al. Epidemiological and virological characteristics of seasonal and pandemic influenza in Lao PDR, 2008-2010. Influenza Other Respir Viruses 2013;7:304-11.

33. The World Bank. Lao PDR 2014 [data]. Available from: http://data. worldbank.org/country/lao-pdr. Accessed July 28, 2014.

34. The World Bank. Philippines 2014 [data]. Available from: http:// data.worldbank.org/country/philippines. Accessed July 28, 2014.

35. Tallo VL, Kamigaki T, Tan AG, et al. Estimating influenza outpatients' and inpatients' incidences from 2009 to 2011 in a tropical urban 
setting in the Philippines. Influenza Other Respir Viruses 2014;8: 159-68.

36. Burmaa A, Tsatsral S, Odagiri T, Suzuki A, Oshitani H, Nymadawa P. Cumulative incidence of pandemic influenza A (H1N1) 2009 by a community-based serological cohort study in Selenghe Province, Mongolia. Influenza Other Respir Viruses 2012;6:e97-104.

37. Osoro EM, Munyua $P$, Muthoka $P$, et al. Hospitalized patients with pandemic (H1N1) 2009, Kenya. Emerg Infect Dis 2011;17:1744-6.

38. Siddharth V, Goyal V, Koushal VK. Clinical-epidemiological profile of influenza A H1N1 cases at a tertiary care institute of India. Indian J Community Med 2012;37:232-5.

39. Jagannatha Rao SR, Rao MJ, Swamy N, Umapathy BL. Profile of H1N1 infection in a tertiary care center. Indian J Pathol Microbiol 2011;54:323-5.

40. Allam RR, Murhekar MV, Tadi GP, Udaragudi PR. Descriptive epidemiology of novel influenza A (H1N1), Andhra Pradesh 2009-2010. Indian J Public Health 2013;57:161-5.

41. Mathur $S$, Dubey $T$, Kulshrestha $M$, et al. Clinical profile and mortality among novel influenza A (H1N1) infected patients: 2009-2010 Jodhpur, Rajasthan pandemic. J Assoc Physicians India 2013;61:627-32.

42. Mehta AA, Kumar VA, Nair SG, K Joseph F, Kumar G, Singh SK. Clinical profile of patients admitted with swine-origin influenza $A$ (H1N1) virus infection: an experience from a tertiary care hospital. J Clin Diagn Res 2013;7:2227-30.

43. Ramakrishna K, Sampath S, Chacko J, et al. Clinical profile and predictors of mortality of severe pandemic (H1N1) 2009 virus infection needing intensive care: a multi-centre prospective study from South India. J Glob Infect Dis 2012;4:145-52.

44. Chudasama RK, Patel UV, Verma PB, et al. Clinico-epidemiological features of the hospitalized patients with 2009 pandemic influenza A (H1N1) virus infection in Saurashtra region, India (September, 2009 to February, 2010). Lung India 2011;28:11-6.

45. Moorthy M, Samuel P, Peter JV, et al. Estimation of the burden of pandemic(H1N1)2009 in developing countries: experience from a tertiary care center in South India. PloS One 2012;7: e41507.

46. Ortiz JR, Jacob ST, West TE. Clinical care for severe influenza and other severe illness in resource-limited settings: the need for evidence and guidelines. Influenza Other Respir Viruses 2013;7(Suppl 2):87-92.

47. Nair H, Brooks WA, Katz M, et al. Global burden of respiratory infections due to seasonal influenza in young children: a systematic review and meta-analysis. Lancet 2011;378:1917-30.

48. Dawood FS, luliano AD, Reed C, et al. Estimated global mortality associated with the first 12 months of 2009 pandemic influenza A H1N1 virus circulation: a modelling study. Lancet Infect Dis 2012;12: 687-95.

49. Simonsen L, Spreeuwenberg P, Lustig R, et al. for the GLaMOR Collaborating Teams. Global mortality estimates for the 2009 influenza pandemic from the GLaMOR project: a modeling study. PLoS Med 2013;10:e1001558.

50. Van Kerkhove MD, Vandemaele KA, Shinde V, et al. for the WHO Working Group for Risk Factors for Severe H1N1pdm Infection. Risk factors for severe outcomes following 2009 influenza A (H1N1) infection: a global pooled analysis. PLoS Med 2011;8: e1001053.

51. Gessner BD, Shindo N, Briand S. Seasonal influenza epidemiology in sub-Saharan Africa: a systematic review. Lancet Infect Dis 2011;11: 223-35.

52. Sertogullarindan $B$, Ozbay B, Gunini $H$, et al. Clinical and prognostic features of patients with pandemic 2009 influenza A (H1N1) virus in the intensive care unit. Afr Health Sci 2011;11:163-70.

53. Yavarian J, Naseri M, Shadab A, Shafiei Jandaghi NZ, Mokhtari Azad T. Epidemiological aspects of pandemic influenza A(H1N1) virus from 2009 to 2011 in Iran. Influenza Other Respir Viruses 2012; 6:e74-6.

54. WHO. WHO Global Influenza Programme Report: Clinical management of influenza and other acute respiratory illness in resource limited settings: learning from the influenza pandemic (H1N1) 2009. 2011. Available from: http://www.who.int/influenza/patient care/ clinical/858-WHOGIPReport_A4_WEB_FA.pdf. Accessed July 20, 2014.

55. Cohen AL, Hellferscee $O$, Pretorius $M$, et al. Epidemiology of influenza virus types and subtypes in South Africa, 2009-2012. Emerg Infect Dis 2014;20:1162-9.

56. Archer B, Cohen C, Naidoo D, et al. Interim report on pandemic H1N1 influenza virus infections in South Africa, April to October 2009: epidemiology and factors associated with fatal cases. Euro Surveill 2009;14. pii: 19369.

57. Cohen C, Moyes J, Tempia S, et al. Severe influenza-associated respiratory infection in high HIV prevalence setting, South Africa, 2009-2011. Emerg Infect Dis 2013;19:1766-74.

58. Webb SA, Pettilā V, Seppelt I, et al. for the ANZIC Influenza Investigators. Critical care services and 2009 H1N1 influenza in Australia and New Zealand. N Engl J Med 2009;361:1925-34.

59. Kumar A, Zarychanski R, Pinto R, et al. for the Canadian Critical Care Trials Group H1N1 Collaborative. Critically ill patients with 2009 influenza A(H1N1) infection in Canada. JAMA 2009;302:1872-9.

60. Rice TW, Rubinson L, Uyeki TM, et al. for the NHLBI ARDS Network. Critical illness from 2009 pandemic influenza A virus and bacterial coinfection in the United States. Crit Care Med 2012;40:1487-98.

61. Beck MA, Nelson HK, Shi Q, et al. Selenium deficiency increases the pathology of an influenza virus infection. FASEB J 2001;15:1481-3.

62. Taylor AK, Cao W, Vora KP, et al. Protein energy malnutrition decreases immunity and increases susceptibility to influenza infection in mice. J Infect Dis 2013;207:501-10.

63. Bellei NC, Carraro E, Castelo A, Granato CF. Risk factors for poor immune response to influenza vaccination in elderly people. Braz J Infect Dis 2006;10:269-73.

64. Adegbola RA, Falade AG, Sam BE, et al. The etiology of pneumonia in malnourished and well-nourished Gambian children. Pediatr Infect Dis J 1994;13:975-82.

65. Katona P, Katona-Apte J. The interaction between nutrition and infection. Clin Infect Dis 2008;46:1582-8.

66. Rothberg MB, Haessler SD, Brown RB. Complications of viral influenza. Am J Med 2008;121:258-64.

67. Short KR, Kroeze EJ, Fouchier RA, Kuiken T. Pathogenesis of influenza-induced acute respiratory distress syndrome. Lancet Infect Dis 2014;14:57-69.

68. Alsadat R, Dakak A, Mazlooms M, et al. Characteristics and outcome of critically ill patients with 2009 H1N1 influenza infection in Syria. Avicenna J Med 2012;2:34-7.

69. Bai L, Gu L, Cao B, et al. Clinical features of pneumonia caused by 2009 influenza $\mathrm{A}(\mathrm{H} 1 \mathrm{N1})$ virus in Beijing, China. Chest 2011;139: 1156-64.

70. Nicolay N, Callaghan MA, Domegan LM, et al. Epidemiology, clinical characteristics and resource implications of pandemic (H1N1) 2009 in intensive care units in Ireland. Crit Care Resusc 2010;12:255-61.

71. Hong SB, Choi EY, Kim SH, et al. for the Korean Society of Critical Care Medicine H1N1 Collaborative. Epidemiological analysis of critically ill adult patients with pandemic influenza A(H1N1) in South Korea. Epidemiol Infect 2013;141:1070-9.

72. Bramley AM, Dasgupta S, Skarbinski J, et al. for the 2009 Pandemic Influenza A(H1N1) Virus Hospitalizations Investigation Team. Intensive care unit patients with 2009 pandemic influenza A (H1N1pdm09) virus infection-United States, 2009. Influenza Other Respir Viruses 2012;6:e134-42.

73. Damak H, Chtara K, Bahloul M, et al. Clinical features, complications and mortality in critically ill patients with 2009 influenza A(H1N1) in Sfax, Tunisia. Influenza Other Respir Viruses 2011;5:230-40.

74. Morens DM, Taubenberger JK, Fauci AS. Predominant role of bacterial pneumonia as a cause of death in pandemic influenza: implications for pandemic influenza preparedness. J Infect Dis 2008; 198:962-70.

75. McCullers JA. The co-pathogenesis of influenza viruses with bacteria in the lung. Nat Rev Microbiol 2014;12:252-62.

76. Madjid M, Miller CC, Zarubaev VV, et al. Influenza epidemics and acute respiratory disease activity are associated with a surge in 
autopsy-confirmed coronary heart disease death: results from 8 years of autopsies in 34,892 subjects. Eur Heart 」 2007;28: 1205-10.

77. Ison MG, Campbell V, Rembold C, Dent J, Hayden FG. Cardiac findings during uncomplicated acute influenza in ambulatory adults. Clin Infect Dis 2005;40:415-22.

78. Karjalainen J, Nieminen MS, Heikkila J. Influenza A1 myocarditis in conscripts. Acta Med Scand 1980;207:27-30.

79. Erden I, Erden EC, Ozhan H, et al. Echocardiographic manifestations of pandemic 2009 (H1N1) influenza A virus infection. J Infect 2010; 61:60-5.

80. Fagnoul D, Pasquier P, Bodson L, Ortiz JA, Vincent JL, De Backer D. Myocardial dysfunction during H1N1 influenza infection. J Crit Care 2013;28:321-7.

81. Dong M, Liu T, Li G. Association between acute infections and risk of acute coronary syndrome: a meta-analysis. Int J Cardiol 2011;147: 479-82.

82. Warren-Gash C, Smeeth L, Hayward AC. Influenza as a trigger for acute myocardial infarction or death from cardiovascular disease: a systematic review. Lancet Infect Dis 2009;9:601-10.

83. Naghavi M, Barlas Z, Siadaty S, Naguib S, Madjid M, Casscells W. Association of influenza vaccination and reduced risk of recurrent myocardial infarction. Circulation 2000;102:3039-45.

84. Gurfinkel EP, de la Fuente RL, Mendiz O, Mautner B. Influenza vaccine pilot study in acute coronary syndromes and planned percutaneous coronary interventions: the FLU Vaccination Acute Coronary Syndromes (FLUVACS) study. Circulation 2002;105: 2143-7.

85. Mamas MA, Fraser D, Neyses L. Cardiovascular manifestations associated with influenza virus infection. Int J Cardiol 2008;130: 304-9.

86. Nichol KL, Nordin J, Mullooly J, Lask R, Fillbrandt K, Iwane M. Influenza vaccination and reduction in hospitalizations for cardiac disease and stroke among the elderly. N Engl J Med 2003;348: 1322-32.

87. Udell JA, Zawi R, Bhatt DL, et al. Association between influenza vaccination and cardiovascular outcomes in high-risk patients: a meta-analysis. JAMA 2013;310:1711-20.

88. Singleton JA, Wortley P, Lu PJ. Influenza vaccination of persons with cardiovascular disease in the United States. Tex Heart Inst J 2004;31: $22-7$.

89. Belle J, Cohen $\mathrm{H}$, Shindo $\mathrm{N}$, et al. Influenza preparedness in lowresource settings: a look at oxygen delivery in 12 African countries. J Infect Dev Ctries 2010;4:419-24.
90. Kushner AL, Cherian MN, Noel L, Spiegel DA, Groth S, Etienne C. Addressing the Millennium Development Goals from a surgical perspective: essential surgery and anesthesia in 8 low- and middleincome countries. Arch Surg 2010;145:154-9.

91. Catania J, Que LG, Govert JA, Hollingsworth JW, Wolfe CR. High intensive care unit admission rate for 2013-2014 influenza is associated with a low rate of vaccination. Am J Respir Crit Care Med 2014;189:485-7.

92. Fischer WA, Hayden F. Antivirals for influenza: novel agents and approaches. In: Vassil ST, Georgiev KW, McGowan J, editors. National Institute of Allergy and Infectious Diseases, NIH, Volume 1: Frontiers in Research. New York, NY: Humana Press; 2008. p. 179-92.

93. Duque J, McMorrow ML, Cohen AL. Influenza vaccines and influenza antiviral drugs in Africa: are they available and do guidelines for their use exist? BMC Public Health 2014;14:41.

94. Ortiz JR, Englund JA, Neuzil KM. Influenza vaccine for pregnant women in resource-constrained countries: a review of the evidence to inform policy decisions. Vaccine 2011;29:4439-52.

95. Steinhoff $\mathrm{MC}$, Omer SB, Roy $\mathrm{E}$, et al. Influenza immunization in pregnancy-antibody responses in mothers and infants. $N$ Engl $J$ Med 2010;362:1644-6.

96. Zaman K, Roy E, Arifeen SE, et al. Effectiveness of maternal influenza immunization in mothers and infants. N Engl J Med 2008;359:1555-64.

97. Muthuri SG, Myles PR, Venkatesan S, Leonardi-Bee J, Nguyen-VanTam JS. Impact of neuraminidase inhibitor treatment on outcomes of public health importance during the 2009-2010 influenza A(H1N1) pandemic: a systematic review and meta-analysis in hospitalized patients. J Infect Dis 2013;207:553-63.

98. Miller PE, Rambachan A, Hubbard RJ, et al. Supply of neuraminidase inhibitors related to reduced influenza A (H1N1) mortality during the 2009-2010 H1N1 pandemic: an ecological study. PloS One 2012; 7:e43491.

99. Ugarte S, Arancibia F, Soto R. Influenza A pandemics: clinical and organizational aspects: the experience in Chile. Crit Care Med 2010; 38(Suppl 4):e133-7.

100. Kahn JM, Goss CH, Heagerty PJ, Kramer AA, O'Brien CR, Rubenfeld GD. Hospital volume and the outcomes of mechanical ventilation. N Engl J Med 2006:355:41-50.

101. Guérin C, Reignier J, Richard JC, et al. for the PROSEVA Study Group Prone positioning in severe acute respiratory distress syndrome. N Engl J Med 2013;368:2159-68.

102. Duke $\mathrm{T}$, Wandi $\mathrm{F}$, Jonathan $\mathrm{M}$, et al. Improved oxygen systems for childhood pneumonia: a multihospital effectiveness study in Papua New Guinea. Lancet 2008;372:1328-33. 